\section{Trump: China could take lead on climate}

Donald Trump has questioned the science behind climate change and committed the United States to withdraw from the Paris agreement, raising concerns that the US contribution to international climate funds will cease (see also Nature http:// doi.org/bs57; 2016). This could cause some of the least-developed countries to lose interest in the Paris process and make many of its essential elements much harder to implement.

The Paris agreement is supposed to start its first review in 2018 - a process that is already fraught with political difficulties that call for strong leadership from the United States, Europe and China. If the United States pulls out and Europe is distracted by problems such as Britain's upcoming exit from the European Union, it could cement China's position as a leader and shaper of global order.

David Victor University of

California, San Diego,

California, USA.

david.victor@ucsd.edu

\section{Trump: keep climate plans to boost jobs}

The economic insecurity of US voters contributed to the election of Donald Trump as president. Alarmingly, he has pledged to support coal usage, withdraw the US commitment to the 2015 Paris climate agreement and reverse the Clean Power Plan, which aims to regulate carbon dioxide emissions from power plants. Although the scientific community cannot back away from climate change, researchers could pay more attention to the economic needs of voters and develop strategies that manage climate risks while bolstering employment and the US economy.

For example, cheap domestic natural gas delivered by fracking has created economic benefit and made the United States an energy exporter. As long as operators control fugitive emissions, gas from fracking will drastically reduce US carbon emissions. If appropriate environmental and social control were to be combined with carbon capture and storage - a technology best implemented by repurposed oil companies - cheap gas could provide both an economic and a climate solution.

The few countries that have already decarbonized their electricity systems have done so by relying on nuclear power. A revitalized US nuclear industry could deliver large amounts of safer and cheaper carbon-free nuclear power - and provide jobs in design, construction and maintenance.

A focus on emissions and technology coupled to economic development, not to ideology and causation, might be more successful with future voters. Jane C. S. Long Oakland, California, USA. janecslong@gmail.com

\section{Trump: unlikely to deter clean energy}

It is unlikely that the US election result alone can derail climate-change mitigation and clean-energy solutions (see also Nature 539, 337-339; 2016). The global momentum in policy and technology is in large part beyond the reach of the next US administration.

Policies to support emissions reduction and clean-energy expansion are already in place around the world. As well as their impact on climate change, these cut pollution, create jobs and boost national competitiveness. These are strong reasons against policy reversal in China and elsewhere.

Some US federal regulations, such as fuel-economy standards, are not easily overturned. In the electricity sector, several US states are well positioned to make up for changes to federal policies that could otherwise limit climate progress, at least over the next $4-8$ years.

This policy momentum is partly due to the success of past policies in driving down the cost of renewables, through technological innovation and economies of scale in private firms. This has encouraged further growth in markets and in worldwide commitments to support decarbonization, which can continue despite new uncertainties about US federal policy.

Jessika Trancik Massachusetts Institute of Technology,

Cambridge, Massachusetts, USA. trancik@mit.edu

\section{Trump: threats to space science?}

President-elect Donald Trump

has declared his support for

NASA's exploration mission

and its human space-flight

programme in particular. As a

professor of planetary and space

sciences, I am concerned that his

opinion may be coloured by the

flag-waving opportunities that

these present, and that he could

be interested in territorial rather

than global benefit (see also

Nature http://doi.org/bs58; 2016).

I am also concerned about statements he has made regarding public-private partnerships, and increasing the role of the private sector in space exploration. As a businessman, he may decide to sell off some of NASA's assets to the private sector, without sufficient thought for safety and governance.

In my view, the international collaborative efforts that are currently in place are the correct way to progress. More-stringent visa regulations could make it harder for UK researchers to take up fellowships and research positions in the United States, hampering our partnerships in space missions and restricting the sharing of data and technology. Monica Grady Open University, Milton Keynes, UK. monica.grady@open.ac.uk

\section{Illness should not curtail PhD funding}

As $\mathrm{PhD}$ students who were diagnosed with cancer during our training, we have first-hand experience of the financial consequences of taking time out for treatment and recovery. Cutting a student's stipend because of serious illness is standard practice in the United Kingdom, compounding the combined stresses of delays to the research project and of the condition itself.

In 3-4 years, UK doctoral students are expected to master new techniques and to generate a solid body of results for research papers and a thesis. Their university and funding contracts reflect this 'apprentice' status and come with restricted rights.

Training grants from the UK research councils typically allow 13 weeks of paid sick leave; the studentship is suspended if an illness is expected to last longer (see www.rcuk.ac.uk/funding/ grantstcs). Other funders may not cover sick leave at all, and most universities do not step in to help.

As a result, a student who is ill can be forced to continue working, to rely on contributions from friends and relatives, or to quit their $\mathrm{PhD}$ - all unacceptable 'punishments' in our view. We suggest that training-grant contracts should be more similar to academic staff contracts in providing at least six months of paid sick leave.

Edwin S. Dalmaijer University of Oxford, UK.

E. A. Claudia Pama University of Cambridge, UK.

Stella Prins University College

London, UK.

edwin.dalmaijer@psy.ox.ac.uk

\section{CORRECTION}

Lihua Yang's Correspondence (Nature 539, 168; 2016)

should have referred to possible rewards to scientists publishing in 'top' international journals, not just in Chinese journals. 